\title{
O QUE SERIA VIVER À LUZ DOS ENSINAMENTOS DE MICHEL DE MONTAIGNE?
}

Emerson Leopoldo Lima de Alencar ${ }^{1}$

Taciana Roberta Correia Cordeiro de Alencar $^{2}$

RESUMO: Consta que certa feita, em 1833, o filósofo americano Ralph Waldo Emerson (18031882) avistara no cemitério Père Lachaise, em Paris, um túmulo de um homem chamado Augusto Collignon, onde na laje tinha a seguinte inscrição: "tinha vivido para fazer o bem, e se formara para a virtude nos Ensaios de Montaigne". Filósofo francês do século XVI, Michel de Montaigne foi fortemente influenciado pelo pensamento helenista, onde extraiu que aceitar com naturalidade a morte é condição indispensável para uma vida prazerosa. Tendo como pano de fundo da sua filosofia reflexões sobre si mesmo e questões do cotidiano, podemos absorver dos seus ensaios, estilo literário do qual é precursor, ensinamentos ainda hoje atuais e interessantes para a instigante arte do bem viver, e é o que se pretende destacar neste artigo.

Palavras-chaves: Montaigne, helenismo, ensinamentos, morte, vida, prazer.

\section{INTRODUÇÃO}

Michel Eyquem de Montaingne nasceu na região de Périgord, na França, em 28 de fevereiro de 1533, falecendo no mesmo local que nascera, no castelo de Montaigne, a 13 de setembro de 1592. Vivera, portanto, no século XVI, quando a França foi palco de guerras travadas entre católicos e protestantes, marcadas pela intolerância e pela violência.

Vivenciou, também, o impacto da revolução copernicana no modo de pensar do de sua época, que até então via um cosmos todo organizado, finito e dirigido pelas leis divinas. Os avanços da ciência afastaram essa concepção de mundo, agora visto como um espaço infinito no qual o homem foi ali colocado como mais um ser qualquer.

Filho de família aristocrática da França, Montaigne teve sólida formação humanística, e desde cedo se interessou por escritores da antiguidade e pela filosofia helenista, sobretudo o estoicismo e o ceticismo. Cícero, Sêneca, Plutarco e Sexto Empírico influenciaram fortemente sua formação filosófica e seu entendimento acerca da vida.

\footnotetext{
${ }^{1}$ Licenciando em Filosofia pela UFPI/EAD
}

${ }^{2}$ Licencianda em Filosofia pela UFPI/EAD 
Foi preparado pelo pai, na realidade, para os negócios públicos, e nele se enveredou por boa parte de sua vida. Até que em 1571 abandonou a vida pública e se refugiou no castelo de sua família. Decidira dedicar o resto de seus dias a meditar e a escrever sobre si e suas experiências, surgindo daí a sua principal obra, Ensaios.

Inaugurou assim um novo gênero literário, que levou o nome de sua obra e cuja característica maior é a possibilidade de se discorrer sobre qualquer tema, sem rigidez de normas e sem a necessidade de demonstrar conclusivamente nada. Procurou assim, Montaigne, divagar de rédeas soltas, sem fronteiras, sobre variados temas, os mais triviais que ocorriam em sua mente e que após o confronto com os clássicos da antiguidade, que ele dominava bem, dali extraia as suas reflexões.

Não espere ver em Montaigne um filósofo acadêmico, de rigor metodológico. Como já dito, ele bebeu na fonte dos helênicos e viveu em um período turbulento de intolerância religiosa, bem como de dúvidas existenciais que marcaram a alma do homem do século XVI em razão das descobertas científicas. A sua filosofia é prática, voltada para arte de bem viver.

E o que seria viver à luz dos ensinamentos de Montaigne? Ao longos desses séculos, anônimos e famosos se inspiraram na sabedoria pragmática desse filósofo francês, justificando assim uma breve síntese de seu pensamento, que até nos dias de hoje, não tão diferentes dos da sua época, parece valer a pena refletir sobre ele.

As pretensões deste artigo, no entanto, são modestas. Quer tão somente introduzir o leitor nas instigantes reflexões desse filósofo da arte do bem viver, não bem explorado nos cursos de graduação em filosofia. A obra Os Ensaios foi produzida e lapidada pelo seu autor durante mais de duas décadas de reflexão na biblioteca do castelo de Montaigne.

\section{MONTAIGNE - UMA SÍNTESE DO SEU PENSAR}

Nada mais pertinente, neste primeiro momento, do que entender o que é filosofar para Montaigne. No volume I de sua obra temos o ensaio assim denominado De como filosofar é aprender a morrer. Inspirando-se em Cícero, entende que a contemplação faz com que a alma se separe do corpo, o que se assemelha à morte, constituindo assim um aprendizado dela; ou mesmo porque as meditações filosóficas podem nos ensinar a não temer a morte ${ }^{3}$.

Para Montaigne é preciso encarar com serenidade a inevitabilidade da morte para que possamos ter uma vida completa independentemente do tempo em que ela durar.

\footnotetext{
${ }^{3}$ Ensaios, I, XX, p. 158
} 
Se pudéssemos escapar dela, diz Montaigne, aconselharia agir diante dela como um covarde foge do perigo. Como ela baterá, inexoravelmente, à porta de todo ser vivente, devemos esperá-la de pé e bem firmes ${ }^{4}$.

É bem verdade que a certeza da morte exerce um grande poder sobre nós. Mas, nos ensina o filósofo francês, para amainar essa vantagem maior que ela dispõe sobre nós, devemos seguir um caminho inverso do habitual: tenhamos a morte a todo instante presente nos nossos pensamentos, mesmo em momentos de festas e divertimentos, como faziam os egípcios ${ }^{5}$.

Lembra Montaigne que os antigos egípcios, nos festivais voltados aos prazeres da carne, mandava expor sobre a mesa um esqueleto humano para rememorar aos convivas a transitoriedade e a fragilidade de suas vidas.

E é isso que sugere Montaigne, pois que para ele refletir sobre a morte é refletir sobre a liberdade. "Quem apreendeu de morrer, desaprendeu de servir; nenbum mal atingirá quem na existência compreendeu que a privação da vida não é um mal; saber morrer nos exime de toda sujeição e constrangimento." ${ }^{6}$

Mas para viver e usufruir dessa curta estada na terra é preciso saúde, pois sem ela a vida perde o encanto, já que toda virtude e sabedoria sem ela se desvanecem ${ }^{7}$. A boa vida, na concepção aqui proposta por Montaigne, não tem como fim necessariamente uma vida longeva, mas sim a possibilidade de gozarmos plenamente os prazeres "físicos' e imateriais.

Prazeres físicos sim, diz Montaigne, pois não somos só espírito; mas ressalta que é tão grave erro se afastar a contragosto dos prazeres naturais como também se apegar demasiadamente a eles. No entanto, bebendo na fonte de Epicuro, põe em maior relevo os prazeres intelectuais, por serem os mais seguros e duráveis ${ }^{8}$.

De acordo com Montaigne, não há porque rejeitar as boas sensações trazidas pelo prazer, pois até quando exercitamos nossas virtudes estamos em busca dessa sensação. O caminho da felicidade passa, portanto, pelos sentidos e não pela razão, o que não significa um sensualismo extremado. Ele rejeita isso, mas é um apreciador dos pequenos prazeres do cotidiano, como beber, comer e ter relações sexuais ${ }^{9}$.

Interessante notar que esse caminho para a felicidade seguido por Montaigne diverge $\mathrm{da}$ linha filosófica que se tinha até então, desde Platão e Aristóteles, que vê a realização humana na contemplação espiritual e no domínio da razão sobre os sentidos ${ }^{10}$.

\footnotetext{
${ }^{4}$ Ensaios, I, XX, p. 162

${ }^{5}$ Ensaios, I, XX, p. 162-163

${ }^{6}$ Ensaios, I, XX, p. 163

7 WEILER, Maurice, 1961, p. 105-106

8 WEILER, Maurice, 1961, p. 106

9 ZIMMER, Robert, 2009, p.57

10 ZIMMER, Robert, 2009, p.57
} 
Não há necessidade, portanto, de nos penitenciarmos, de nos afastarmos com um enorme sofrer daqueles prazeres que satisfazem o nosso corpo, o espírito não ficará com ciúmes, basta que tenhamos moderação, tema inclusive de um ensaio de Montaigne.

Em Da moderação, ele explicita melhor essa questão e alerta que até as virtudes podem se tornar um vício se praticadas com demasia avidez e violência. E diz: "Aprecio os caracteres moderados e prudentes: ultrapassar a medida ainda que no sentido do bem, é coisa que me espanta, se não me incomoda, e a que não sei como chamar."111

Em qualquer época que estejamos, seja em pleno século XVI ou nos dias atuais, é de se ver sempre com bons olhos, e aplaudir até, o amor e o cuidado de uma mãe com a sua prole, pois é um sentimento que faz pulsar a vida aqui na Terra. Mas até essa virtude em excesso pode ser maléfica, comprometendo por vezes o próprio desenvolvimento da criança.

Não raro vemos jovens com graves problemas psicológicos e de socialização muito em razão desse excesso de cuidados.

E quem diria até mesmo a filosofia levada ao extremo pode ser prejudicial, diz Montaigne, apoiado nos diálogos de Platão, e aconselha que não nos dediquemos a ela além dos limites da utilidade. E assim expõe:

Praticada com moderação é agradável e cômoda; mas se ultrapassa tais limites ela acaba tornando o homem insociável e viciado, desdenhoso da religião e das leis que nos governam, inimigo da boa conversação, dos prazeres permitidos, incapaz de exercer funções públicas, de prestar socorro a alguém e a si próprio, bom para ser impunimente esbofeteado. ${ }^{12}$

\section{MONTAIGNE E UMA REFLEXÃO SOBRE A BARBARIDADE NO MUNDO}

Montaigne não tem rédias presas no pensamento; filosofa sobre os mais variados temas da vida cotidiana sem a pretensão de criar um sistema filosófico. Trata da embriaguez, dos órgãos genitais etc. Tudo pode ser objeto de sua filosofia; não poderia escapar de suas reflexões, portanto, a pretensa superioridade da civilização européia.

As atrocidades cometidas na guerra civil que se instalou na França durante o século XVI entre católicos e protestantes nos dá conta de quanto o homem pode cometer absurdos contra aqueles que pensam diferente dele.

\footnotetext{
${ }^{11}$ Ensaios, I, XXX, p. 254

12 Ensaios, I, XXX, p. 255
} 
No ensaio Os canibais percebemos o quanto Montaigne estava à frente de seu tempo. Relata o contato tido com os povos do Novo Mundo e os compara com o eurocentrismo vigente em sua terra e as barbaridades que ali vivenciara em razão da religião e da política.

A Europa erudita e supostamente superior em termos de civilidade chamava de "selvagens" os índios da América por estes viverem próximos ao estado da natureza, como diria Hobbes ou Locke. O europeu da época ficava escandalizado com as notícias de canibalismo praticadas por esses povos "bárbaros".

Michel de Montaigne guiava seu pensamento por outro rumo, por outra estrada. Não lhe parecia selvagens aqueles índios pelo simples fato de não haverem se distanciado quase nada de sua condição primitiva.

Ao revés, ficou encantado com a beleza de uma organização social indígena, subsistindo com tanta igualdade entre o seus membros sem maiores artifícios. Inexistia hierarquia política, ricos ou pobres. Segundo o filósofo francês, acaso Platão a tivesse conhecido, A República lhe pareceria algo distante de tamanha perfeição ${ }^{13}$.

Em um ataque sutil ao eurocentrismo, Montaigne entendia que esses "selvagens" estavam na realidade em um patamar superior ao do homem dito civilizado porquanto estando mais integrados à natureza seus desejos estariam mais orientados para as necessidades naturais, e por isso escapavam do fardo do luxo e do excesso ${ }^{14}$.

Ora, mas o que dizer desses povos que matam seus inimigos aprisionados a bordoadas, comendo-os em seguida? Responde Montaigne a esses civilizados com uma ironia fina que lhe é característica:

\begin{abstract}
Não me parece excessivo julgar bárbaros tais atos de crueldade, mas que o fato de condenar tais defeitos não nos leve à cegueira acêrca dos nossos. Estimo que é mais bárbaro comer um homem vivo do que o comer depois de morto; e é pior esquartejar um corpo entre suplícios e tormentos e o queimar aos poucos, ou entregá-lo a cães e porcos, a pretexto de devoção e fé, como, não somente o lemos mas vimos ocorrer entre vizinhos nossos conterrâneos; e isso em verdade é bem mais grave do que assar e comer um homem previamente executado. ${ }^{15}$
\end{abstract}

E mais adiante arremata: "Podemos portanto qualificar esses povos como bárbaros em dando apenas ouvidos à inteligência, mas nunca se o compararmos a nós mesmos, que o excedemos em tôda sorte de barbaridades. ${ }^{116}$

Portanto, Montaigne via na cultura européia da sua época, que não é tão diferente do chamado mundo civilizado de hoje, um equívoco fundamental: sua falta de limites, sua busca

\footnotetext{
13 Ensaios, I, XXXI, 262

14 ZIMMER, Robert, 2009, p.56

15 Ensaios, I, XXXI, 264

${ }^{16}$ Ensaios, I, XXXI, 264
} 
interminável por mais e mais, que a conduziria a um esforço destrutivo. E sugeria que ao invés de se avaliar a superioridade de uma cultura em relação a outra, que o homem seja mais tolerante e tenha mais disposição para aprender ${ }^{17}$.

\section{MONTAIGNE DIANTE DA INFINITUDE DO UNIVERSO}

A Revolução Copernicana, a substituição do modelo geocêntrico para a adoção do heliocentrismo, desestabilizou o homem na Terra. O mundo que lhe parecia fechado, estável, regido por lei divinas, onde sua presença era fundamental para a ordem cósmica, agora lhe parece um infinito espaço desconhecido no qual passa a perambular aflitamente como um ser qualquer.

Esse marco na história da humanidade repercutiu profundamente na filosofia. Enquanto Montaigne, diante de toda essa insegurança do homem frente a um Universo infinito, adota uma atitude serena e convida o homem a ocupar novamente um espaço na natureza, opta Pascal, ante o drama da existência humana, por buscar abrigo na religião e na fé ${ }^{18}$.

Mas o fato de Montaigne ter essa postura diante da vida e das incertezas do mundo não o fazia necessariamente um ateu. Ao contrário, se dizia católico, porém longe de ser um dogmático. Tanto que dizia "somos cristãos como somos perigordinos ou alemães" ${ }^{\prime \prime}$. Ou seja, era cristão mas poderia ser mulçumano ou judeu acaso nascesse em outra região ou família.

Uma vida encarada assim com tanta sabedoria, bom senso, tolerância e prudência serve de inspiração para muitos; e com esse filósofo francês não foi diferente: o pensador americano Ralph Waldo Emerson (1803-1882) avistara no cemitério Père Lachaise, em Paris, um túmulo de um homem chamado Augusto Collignon, onde na laje tinha a seguinte inscrição: "tinha vivido para fazer o bem, e se formara para a virtude nos Ensaios de Montaigne". ${ }^{20}$

\section{CONSIDERAÇÕES FINAIS}

Mais de quatro séculos nos afasta de Montaigne. Vivemos uma época onde pululam a todo instante doutores da felicidade com receituários prontos para alcançarmos a tão sonhada ataraxia, objeto da filosofia dos helenistas e de cobiça do homem do século XVI e das mais diversas épocas, inclusive a nossa.

\footnotetext{
17 ZIMMER, Robert, 2009, p.56

18 ZIMMER, Robert, 2009, p.80

${ }^{19}$ Ensaios, II, XII, p...

${ }^{20}$ EMERSON, Ralph Waldo, s/d, p.87
} 
É de se questionar, assim, se Montaigne seria capaz ainda de instigar seguidores tais como aquele ilustre desconhecido que jaz no cemitério Père Lachaise, em Paris. Dúvida que se esvai, no entanto, no exato momento em que nos debruçamos na leitura de um de seus ensaios porquanto suas lições acerca da arte de bem viver ainda continuam bem atuais, até porque em pleno século XXI nos deparamos ainda com uma intolerância cada vez mais recrudescente.

Arejar a mente para aceitar o diferente é preciso se quisermos aproveitar na plenitude nossa curta visita a esse mundo, que sempre será obscuro e assustador, por mais que avancemos na ciência ou nos entreguemos à religião. Montaigne ainda pode nos ajudar...

\section{REFERÊNCIAS}

EMERSON, Ralph Waldo. Homens Representativos. Trad. Alfredo Gomes. Rio de JaneiroRJ: Ed Tecnoprint S.A, [19..], 154 p.

MONTAIGNE, Michel. Ensaios. Trad. Sérgio Milliet. Porto Alegre-RS: Editora Globo, 1961, v I e II.

WEILER, Maurice. Para conhecer o pensamento de Montaigne. In: MONTAIGNE, Michel. Ensaios. Trad. Sérgio Milliet. Porto Alegre-RS: Editora Globo, 1961, v III.

ZIMMER, Robert. Portal da Filosofia: uma entrada para as obras clássicas. Trad. Mariane Vieira Lisboa e Rita de Cássia Machado. São Paulo-SP: Ed. WMF Martins Fontes Ltda, 2009, 225 p. 